\title{
Synthesis of nanocrystalline fluorinated hydroxyapatite by microwave processing and its in vitro dissolution study
}

\author{
N RAMESHBABU, T S SAMPATH KUMAR and K PRASAD RAO* \\ Department of Metallurgical and Materials Engineering, Indian Institute of Technology Madras, Chennai 600 036, India
}

\begin{abstract}
Synthetic hydroxyapatite, $\left(\mathrm{Ca}_{10}\left(\mathrm{PO}_{4}\right)_{6}(\mathrm{OH})_{2}, \mathrm{HA}\right)$, is an important material used for orthopedic and dental implant applications. The biological hydroxyapatite in the human bone and tooth is of nanosize and differs in composition from the stoichiometric HA by the presence of other ions such as carbonate, magnesium, fluoride, etc. Osseointegration is enhanced by using nanocrystalline HA. This stimulates the interest in synthesizing nanocrystalline $\mathrm{HA}$ by different routes and among the methods, microwave processing seems to form the fine grain size and uniform characteristic nanocrystalline materials. Fluorinated hydroxyapatite, $\left(\mathrm{FHA}, \mathrm{Ca}_{10}\left(\mathrm{PO}_{4}\right)_{6}(\mathrm{OH})_{2-x} \mathrm{~F}_{x}\right)$, possesses higher corrosion resistance in biofluids than pure $\mathrm{HA}$ and reduces the risk of dental caries. The present work deals with the synthesis of nanocrystalline FHAs by microwave processing. The crystal size and morphology of the nanopowders were examined by $X$-ray powder diffraction (XRD) and transmission electron microscopy (TEM) methods. The functional groups present in FHA powders were ascertained by Fourier transform infrared spectroscopy (FT-IR) and laser Raman spectroscopy. Since the physiological stability is an important parameter while selecting the material for implantation, the in vitro dissolution studies of FHAs with different fluorine contents were carried out.
\end{abstract}

Keywords. Fluorinated hydroxyapatite; nanocrystalline; microwave synthesis; dissolution.

\section{Introduction}

Hydroxyapatite is a major mineral component of the calcified tissues (i.e. bones and teeth). Synthetic hydroxyapatite, $\left[\mathrm{HA}, \mathrm{Ca}_{10}\left(\mathrm{PO}_{4}\right)_{6}(\mathrm{OH})_{2}\right]$, has been extensively used as an implant material for bone substitute owing to its excellent osteoconductive properties (Groot 1980). Synthetic HA has been used for a variety of other biomedical applications like matrices for controlled drug release, bone cements, tooth paste additive, dental implants etc (Itokazu et al 1998; Legeros 1998; Niwa et al 2001; Kenny and Buggy 2003). When $\mathrm{OH}^{-}$groups in $\mathrm{HA}$ are partially substituted by $\mathrm{F}^{-}$, fluorine substituted hydroxyapatite, [FHA, $\mathrm{Ca}_{10}\left(\mathrm{PO}_{4}\right)_{6}$ $\left.(\mathrm{OH})_{2-x} \mathrm{~F}_{x}, 0<x<2\right]$, is obtained. If the substitution is completed, fluorapatite [FA, $\left.\mathrm{Ca}_{10}\left(\mathrm{PO}_{4}\right)_{6} \mathrm{~F}_{2}\right]$, is formed. The presence of fluorine $(\mathrm{F})$ in saliva and blood plasma is important for normal skeletal and dental development. It has been suggested that fluorine intake of $1.5-4 \mathrm{mg} /$ day significantly reduces the risk of dental caries (Boivin 1990). Fluorine substitution in HA enhances the acid resistance and stability of hydroxyapatite. Recent studies have shown that the incorporation of fluorine into HA induced better biological response (Chen and Miao 2005; Yoon et al 2005).

Bone is in a constant state of remodeling with osteoblast cells producing and mineralizing new bone matrix, osteo-

\footnotetext{
*Author for correspondence (kpr@iitm.ac.in)
}

cytes maintaining the matrix and osteoclast cells resorbing the matrix. Resorbing the bone by osteoclasts is an acidsecreting mechanism that involves carbonic anhydrase, an enzyme present in osteoclasts, which is believed to play a key role in the resorption. The dissolved minerals then reenter the bloodstream and are carried to different parts of the body. Osteoblasts are responsible for the formation of new bone. They start by secreting collagen and then coat with non-collagenous proteins that have the ability to hold minerals, mostly calcium and phosphate, from the bloodstream, leading to new bone formation. Increased bone resorption is an important determinant in pathophysiology of osteoporosis and many other metabolic bone diseases.

Compared to the coarse grained HA, nanocrystalline hydroxyapatite (HA) has been proved to be of greater biological efficacy in terms of osteoblast adhesion, proliferation and the formation of new bone on its surface (Webster et al 2000). Nanocrystalline HA can be synthesized by several routes such as co-precipitation process, mechanochemical reaction, precipitation using emulsion, microwave synthesis, template and sol-gel techniques. The microwave synthesis is a fast, simple and efficient method to prepare nanosized HA with uniform characteristics due to rapid homogenous nucleation (Rameshbabu et al 2005).

The present work aims to synthesize nanocrystalline FHAs with different fluorine contents by microwave processing and to study the effect of fluorine substitution 
on the dissolution characteristics of apatite under physiological conditions of osteoclastic bone resorption, i.e. at a pH between 4 and 5 (Tadic et al 2002). The body seems to fine-tune the solubility properties of its different apatite minerals (i.e. bone apatite, enamel apatite) via ionic substitutions; the specific apatite in bone is amenable to dissolution, whereas slightly different apatite in enamel resists dissolution (Wopenka and Pasteris 2005). Therefore, studying the dissolution properties of fluorinated hydroxyapatites with different fluorine contents is important to understand its suitability for different implant applications.

\section{Materials and methods}

Nanocrystalline fluorinated hydroxyapatites with different fluorine contents were synthesized through a microwave accelerated wet chemical reaction. Analytical grade calcium hydroxide $\left[\mathrm{Ca}(\mathrm{OH})_{2}\right.$, E. Merck, Germany], diammonium hydrogen phosphate [DAP, $\left(\mathrm{NH}_{4}\right)_{2} \mathrm{HPO}_{4}$, E. Merck, Germany], and ammonium fluoride [ $\mathrm{NH}_{4} \mathrm{~F}$, E. Merck, Germany] were used as precursor materials for the preparation of nanocrystalline FHAs. A $0.25 \mathrm{M}$ ammonium fluoride solution and 0.3 M DAP solution was prepared separately and these two solutions were added to a $0.3 \mathrm{M}$ calcium hydroxide aqueous suspension under vigorous stirring conditions. These reactants in aqueous medium with a $\mathrm{pH}$ of 11 (Thermo Orion 420A, USA) were immediately subjected to microwave irradiation for about $30 \mathrm{~min}$ in a domestic microwave oven (Sharp R-330F, 2.45 GHz, $1100 \mathrm{~W}$ power). The precipitate was thoroughly washed with distilled water to remove impurity ions $\left(\mathrm{NH}^{4+}\right)$. The product obtained after filtration was oven-dried overnight at $90^{\circ} \mathrm{C}$ and the flakes were powdered using an agate mortar and pestle. Ammonium fluoride was added in varying quantities to prepare powders with a chemical composition of $\mathrm{Ca}_{10}\left(\mathrm{PO}_{4}\right)_{6}$ $(\mathrm{OH})_{2-} \mathrm{F}_{x}$ with $x=0 \cdot 4,1 \cdot 2,2$. These compositions correspond to a $20 \%, 60 \%$ and $100 \%$ fluoride substitution for $\mathrm{OH}^{-}$groups and can be further referred to as $20 \mathrm{FHA}$, 60 FHA and FA in this paper. A small amount of powder of each composition was heat-treated at $900^{\circ} \mathrm{C}$ for $2 \mathrm{~h}$ in a box furnace at a ramp speed of $10^{\circ} \mathrm{C} / \mathrm{min}$ and furnace cooled (further referred to as heat-treated condition).

The powders were subjected to various investigations using experimental techniques like XRD (Shimadzu, XD-D1, Japan) for the phases present and crystal size measurement, FT-IR (Perkin Elmer, Spectrum One, USA) and Raman spectroscopy (micro Raman system, Renishaw $1000, \mathrm{UK})$ for the functional groups present, and TEM (Philips CM12 STEM, Netherlands) for the particle size and morphology. The diffraction peak at $25.9^{\circ}$ was chosen for calculation of the crystallite size by Scherrer formula since it is sharper and isolated from others. This peak assigns to (002) Miller's plane family and shows the crystal growth along the $c$ axis of HA crystalline structure. The
FT-IR spectra were obtained over the region $450-4000 \mathrm{~cm}^{-1}$ in pellet form for $1 \mathrm{mg}$ powder samples mixed with $200 \mathrm{mg}$ spectroscopic grade $\mathrm{KBr}$ (Merck, Germany). Spectra were recorded at $4 \mathrm{~cm}^{-1}$ resolution averaging 80 scans. For TEM analysis, the powder sample was ultrasonically dispersed in ethanol to form dilute suspensions and then a few drops were deposited on the carbon coated copper grids.

The in vitro dissolution studies of 20 FHA, 60 FHA and FA were carried out with the conditions of osteoclastic resorption, i.e. at a $\mathrm{pH}$ of about 4.5 (Tadic et al 2002) in order to simulate general remodelling of the skeletal system. Compacts were prepared by uniaxially pressing $300 \mathrm{mg}$ of powder at $300 \mathrm{MPa}$ in a $10 \mathrm{~mm}$ diameter stainless steel die. The initial weight of the compacted samples was noted. The compacted samples were immersed into water $(100 \mathrm{ml}$ each) at $\mathrm{pH} 4.5$ and temperature, $37^{\circ} \mathrm{C}$. The $\mathrm{pH}$ was checked and adjusted at regular intervals $(3 \mathrm{~h})$. If the $\mathrm{pH}$ was increased due to neutralization of the basic calcium phosphate, 0.001 $\mathrm{N} \mathrm{HNO}_{3}$ was added in order to maintain an average $\mathrm{pH}$ of $4 \cdot 5$. The samples were taken out after $72 \mathrm{~h}$ and weighed after drying.

\section{Results and discussion}

Figure 1 shows the XRD patterns of 20 FHA, 60 FHA and FA in as synthesized condition. The XRD peaks were markedly broader, which suggested that particles were nanosized. The crystal sizes of the synthesized powders measured by the (002) peak broadening, using Scherrer formula are $25 \mathrm{~nm}, 25 \mathrm{~nm}, 27 \mathrm{~nm}$ for the $20 \mathrm{FHA}, 60 \mathrm{FHA}$, FA, respectively. The fraction of crystalline phase $\left(X_{\mathrm{c}}\right)$ in HA powder has been calculated by the following equation:

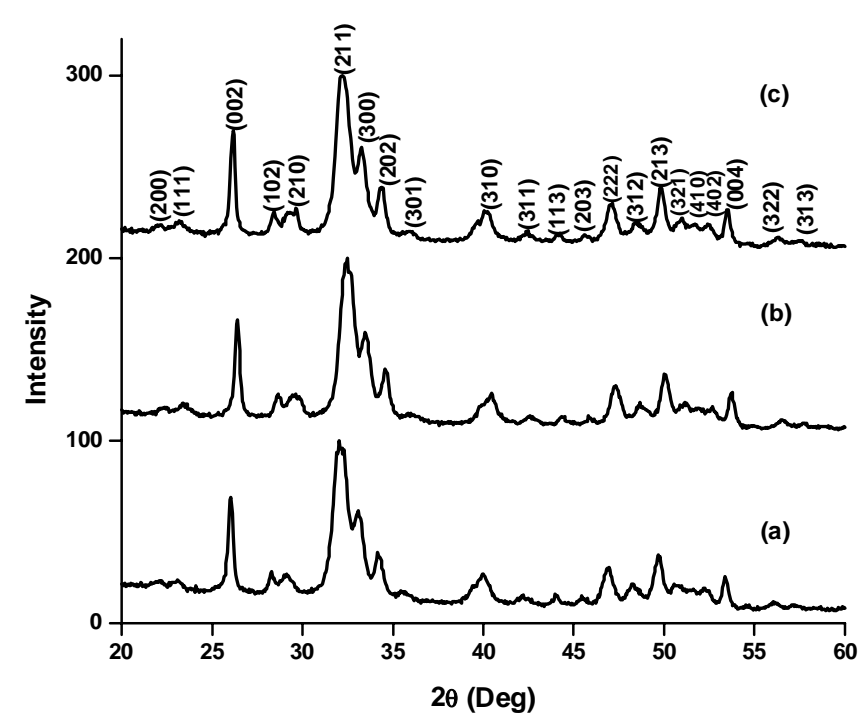

Figure 1. The XRD patterns of $20 \mathrm{FHA}(\mathbf{a}), 60 \mathrm{FHA}(\mathbf{b})$ and FA (c) samples in as synthesized condition. 


$$
\left.X_{\mathrm{c}} \approx 1-\left(V_{112 / 300}\right) / I_{300}\right),
$$

where $I_{300}$ is the intensity of the (300) diffraction peak and $V_{112 / 300}$ the intensity of the hollow between (112) and (300) diffraction peaks (Landi et al 2000). The crystallinity of FHAs increased with increase in fluoride content as evidenced by the $19 \%, 24 \%$ and $28 \%$ for the 20 FHA, 60 FHA and FA, respectively. Crystallinity of 60 FHA and FA are higher than 20 FHA, which seems to indicate that the fluoride concentration increases the driving force for the apatite crystal growth during precipitation. Fluo-

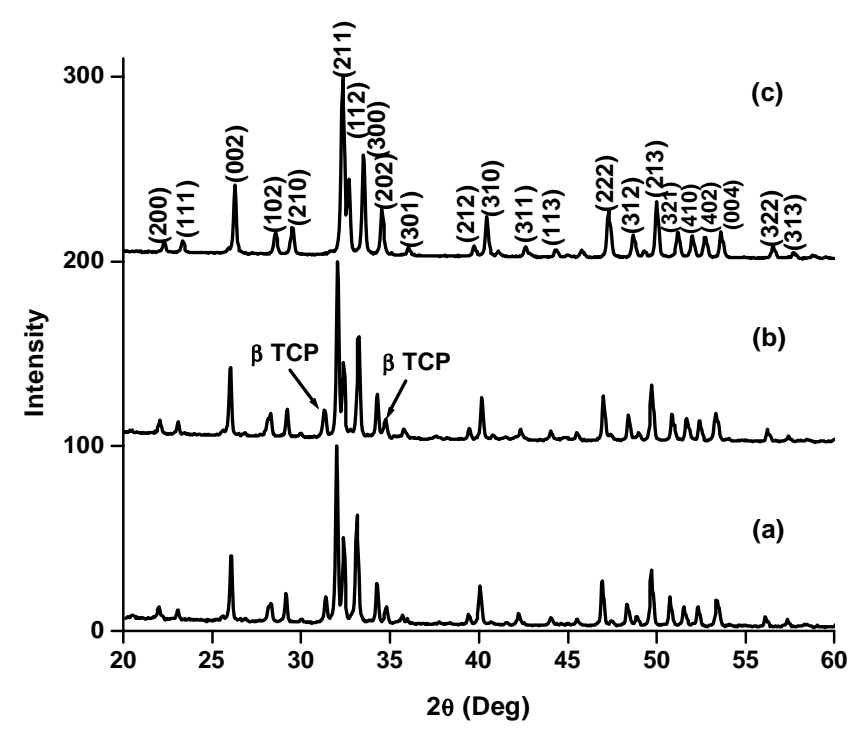

Figure 2. The XRD patterns of 20 FHA (a), 60 FHA (b) and FA (c) samples in $900^{\circ} \mathrm{C}$ heat-treated condition. rine tends to decrease the strain on the apatite lattice and thereby increased stability of the apatite structure (Luis et al 2003). The diffraction peaks of the $900^{\circ} \mathrm{C}$ heat-treated samples are well resolved as shown in figure 2 . The presence of $\beta$-TCP phase was observed in heat-treated samples of 20 FHA and 60 FHA and it was not detected in FA indicating its thermal stability.

The bright field transmission electron microscopic images of 20 FHA and FA nanoparticles in as synthesized condition are shown in figures $3(\mathrm{a})$ and (b), respectively. The 20 FHA particles were of nano-plate like morphology with $15 \mathrm{~nm}$ width and $60 \mathrm{~nm}$ length, the size comparable to that of the bone apatite (Weiner and Wagner 1998). The particles were a bit thinner and longer with more irregular and less clear contour. In addition, the particles showed high tendency to agglomerate. On the other hand, FA (figure 3(b)) particles were a bit thicker (20-25 nm) and lengthier (70-80 nm) than 20 FHA nanoparticles, with clear contours and less agglomeration. TEM results indicate that fluoride concentration increases the driving force for the apatite crystal growth during precipitation. Instrumental broadening and the broadening due to strain, which were not taken into account for crystallite size measurement by XRD using Scherrer's formula, might be the reason for the smaller average crystallite sizes in XRD, compared to TEM images. However, it is confirmed by XRD and TEM that the powders in as synthesized condition are of nanosize (below $100 \mathrm{~nm}$ ).

Figure 4 shows the FT-IR spectra of 20 FHA, 60 FHA and FA powders subjected to heat-treatment at $900^{\circ} \mathrm{C}$ for $2 \mathrm{~h}$. The characteristic bands (listed in table 1) exhibited in the 20 FHA spectra are assigned here: (a) Two bands were
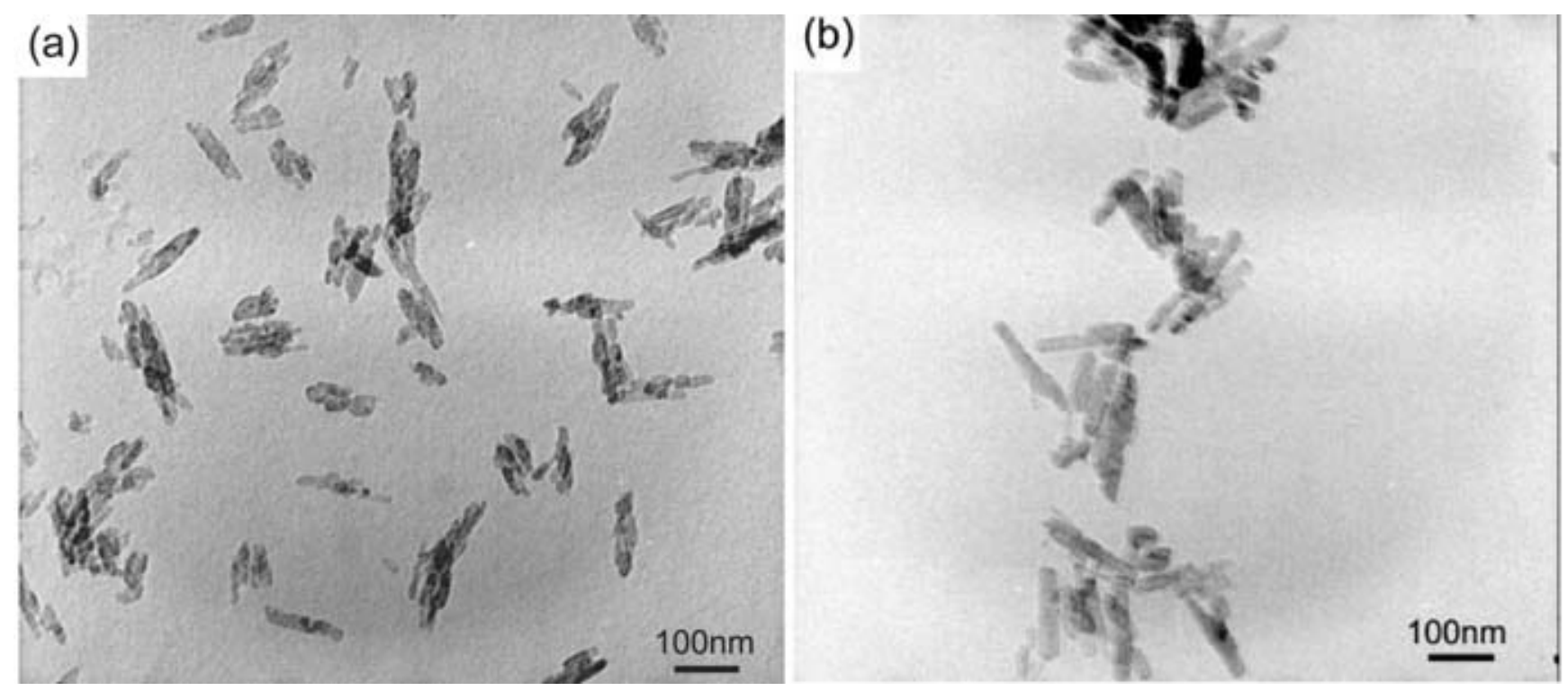

Figure 3. The TEM morphology of 20 FHA (a) and FA (b) samples in as synthesized condition. 
Table 1. Infrared and Raman bands assigned for 20 FHA, 60 FHA and FA.

\begin{tabular}{|c|c|c|c|c|c|c|}
\hline \multirow[b]{2}{*}{ Assignment } & \multicolumn{3}{|c|}{ Infrared frequency $\left(\mathrm{cm}^{-1}\right)$} & \multicolumn{3}{|c|}{ Raman shift $\left(\mathrm{cm}^{-1}\right)$} \\
\hline & 20 FHA & 60 FHA & FA & 20 FHA & 60 FHA & FA \\
\hline \multirow{2}{*}{$\mathrm{OH}^{-}$(stretching) } & 3570 & - & - & 3570 & - & - \\
\hline & 3544 & 3544 & - & 3537 & - & - \\
\hline \multirow{5}{*}{$v_{3} \mathrm{PO}_{4}^{3-}$ stretch } & 1092 & 1092 & 1092 & 1079 & 1079 & 1079 \\
\hline & 1046 & 1046 & 1046 & 1058 & 1058 & 1058 \\
\hline & & & & 1050 & 1050 & 1050 \\
\hline & & & & 1042 & 1042 & 1042 \\
\hline & & & & 1034 & 1034 & 1034 \\
\hline$v_{1} \mathrm{PO}_{4}^{3-}$ stretch & 962 & 962 & 962 & 964 & 964 & 964 \\
\hline $\mathrm{CO}_{3}^{2-}$ & 716 & 747 & - & - & - & - \\
\hline $\mathrm{OH}^{-}$(librational) & 639 & - & - & - & - & - \\
\hline \multirow[t]{3}{*}{$v_{4} \mathrm{PO}_{4}^{3-}$ bend } & 603 & 603 & 603 & 609 & 609 & 609 \\
\hline & 574 & 574 & 574 & 592 & 592 & 592 \\
\hline & & & & 581 & 581 & 581 \\
\hline \multirow[t]{2}{*}{$v_{2} \mathrm{PO}_{4}^{3-}$ bend } & 471 & 471 & 471 & 448 & 448 & 448 \\
\hline & & & & 432 & 432 & 432 \\
\hline
\end{tabular}

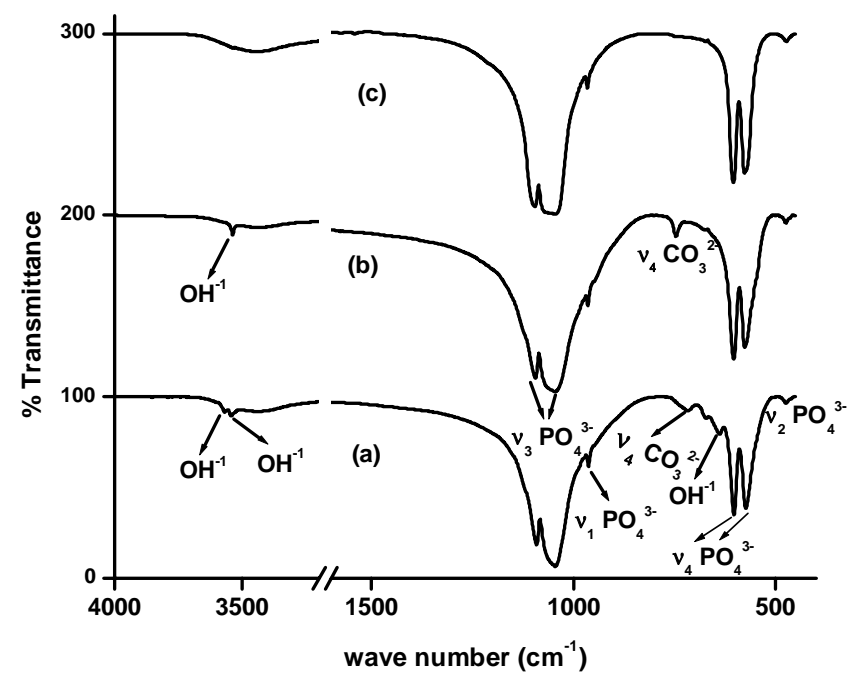

Figure 4. The FTIR spectra of 20 FHA (a), 60 FHA (b) and FA (c) samples in $900^{\circ} \mathrm{C}$ heat-treated condition.

observed at $3570 \mathrm{~cm}^{-1}, 3544 \mathrm{~cm}^{-1}$ due to the stretching mode of hydrogen-bonded $\mathrm{OH}^{-}$ions, $\mathrm{OH} \ldots \mathrm{OH}$ and $\mathrm{OH} \ldots \mathrm{F}$, respectively. The $639 \mathrm{~cm}^{-1}$ arise from librational mode of $\mathrm{OH}^{-}$ions. (b) The bands at $1092 \mathrm{~cm}^{-1}$ and $1046 \mathrm{~cm}^{-1}$ arise from $v_{3} \mathrm{PO}_{4}$, the band at $962 \mathrm{~cm}^{-1}$ arise from $v_{1} \mathrm{PO}_{4}$, and the bands at 603 and $574 \mathrm{~cm}^{-1}$ arise from $v_{4} \mathrm{PO}_{4}$ (Harrison et al 2004). (c) The band at $716 \mathrm{~cm}^{-1}$ arise from $\mathrm{CO}_{3}$ ions (Harrison et al 2004). The phosphate bands in 60 FHA and FA are slightly shifted compared to 20 FHA. In 60 FHA, $\mathrm{OH}^{-}$band appears only at $3544 \mathrm{~cm}^{-1}$ indicating that the $\mathrm{OH} . . \mathrm{F}$ interaction influences all the $\mathrm{OH}^{-}$ions present in the compound. $\mathrm{OH}^{-}$bands completely disappeared in $\mathrm{FA}$, suggesting that substantial amount of fluoride has been substituted for the hydroxyl groups. The carbonate band, which appears at $716 \mathrm{~cm}^{-1}$ for 20 FHA has shifted to $747 \mathrm{~cm}^{-1}$ in 60 FHA. The laser Raman spectra of 20 FHA

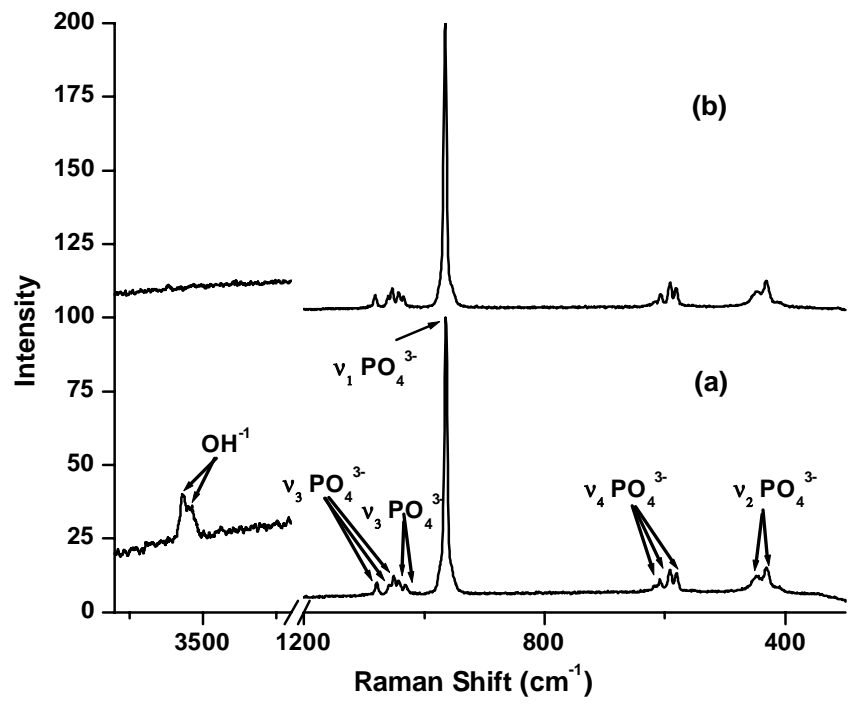

Figure 5. The Raman spectra of 20 FHA (a) and 60 FHA (b) samples in $900^{\circ} \mathrm{C}$ heat-treated condition.

and 60 FHA heat-treated samples are shown in figure 5. The 20 FHA and 60 FHA spectra show all the $\mathrm{PO}_{4}^{3-}$ bands (see table 1) such as $v_{2} \mathrm{PO}_{4}^{3-}\left(432 \mathrm{~cm}^{-1}, 448 \mathrm{~cm}^{-1}\right), v_{4}$ $\mathrm{PO}_{4}^{3-}\left(581 \mathrm{~cm}^{-1}, 592 \mathrm{~cm}^{-1}, 609 \mathrm{~cm}^{-1}\right), v_{1} \mathrm{PO}_{4}^{3-}\left(964 \mathrm{~cm}^{-1}\right), v_{3}$ $\mathrm{PO}_{4}^{3-}\left(1034 \mathrm{~cm}^{-1}, 1042 \mathrm{~cm}^{-1}, 1050 \mathrm{~cm}^{-1}, 1058 \mathrm{~cm}^{-1}\right.$, $\left.1079 \mathrm{~cm}^{-1}\right)$. Apart from the $\mathrm{PO}_{4}^{3-}$ bands, the hydroxyl bands also appear at $3570 \mathrm{~cm}^{-1}$ and $3537 \mathrm{~cm}^{-1}$ for 20 FHA, but it was found to be absent in 60 FHA suggesting that substantial amount of fluoride has been substituted for the hydroxyl groups. The intense bands observed in Raman spectra at $580 \mathrm{~cm}^{-1}$ and $590 \mathrm{~cm}^{-1}$ assigned to $V_{4} \mathrm{PO}_{4}^{3-}$ are not visible in FT-IR spectra.

Figure 6 shows the relative weights of 20 FHA, 60 FHA and FA samples after $72 \mathrm{~h}$ in osteoclastic resorption conditions. The chemical stability of the FHAs at osteoclastic re- 


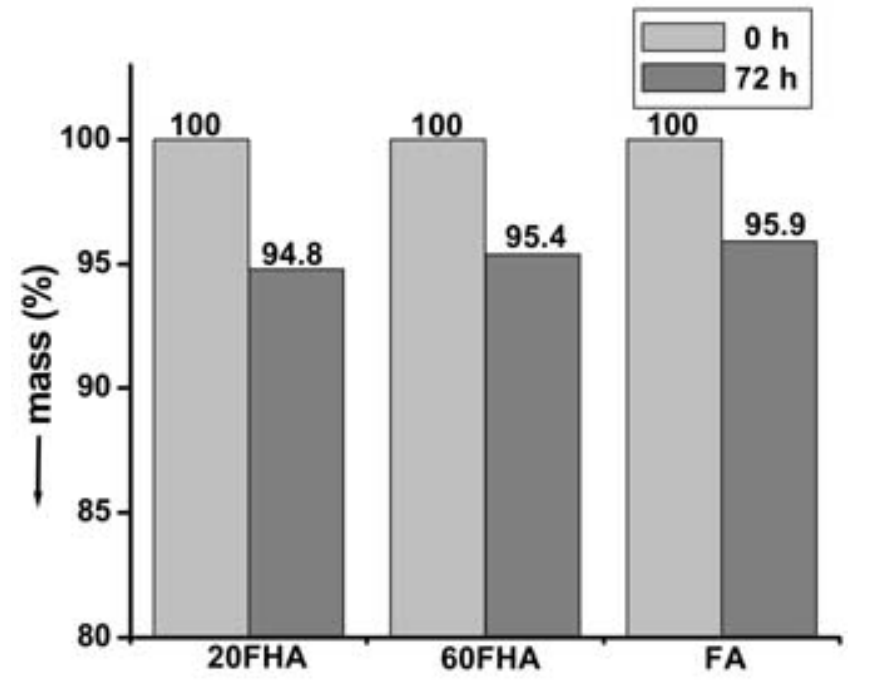

Figure 6. Solubility of $20 \mathrm{FHA}, 60 \mathrm{FHA}$ and $\mathrm{FA}$ at $\mathrm{pH}=4 \cdot 5$ (simulation of osteoclastic resorption).

sorption conditions, increased with increase in fluoride substitutions, as evidenced by the 60 FHA and FA with lower rate of dissolution. These in vitro results suggest that the fluoride substitutions in HA offer the ability to prepare HAs with different degrees of solubility. The degree of fluoridation in the enamel of the tooth is as high as $50 \%$, i.e. $50 \%$ of the $\mathrm{OH}^{-}$groups in $\mathrm{HA}$ is substituted by $\mathrm{F}^{-}\left[\mathrm{Ca}_{10}\left(\mathrm{PO}_{4}\right)_{6}(\mathrm{OH})_{1} \mathrm{~F}_{1}\right]$. In the practical context of the mouth, 60 FHA or FA may be suitable for tooth applications, because these compounds are less soluble than the 20 FHA in acidic conditions (like those produced by oral bacteria or by soft drinks). Apart from enhancing the acid resistance of the hydroxyapatite, fluorine is thought to stimulate bone growth directly by suppressing the maturation of osteoclasts, inhibiting phagocyte cell activity and minimizing proliferation of fibroblasts (Pullen and Gross 2005). The fluorine content in the natural bone is $<1 \mathrm{wt} . \%$. The nanocrystalline 20 FHA (F $\sim 0.75$ wt. \%) possessing slightly higher solubility than the nanocrystalline 60FHA or FA under the conditions of osteoclastic resorption may be a preferred material for bone applications, where higher solubility is required to participate in the general remodelling of the skeletal system. The nanocrystalline HAs with different fluorine contents (FHAs and FA), having different solubility behaviour, would enable the surgeons to choose the appropriate material for the needs of specific application.

\section{Conclusions}

Nanocrystalline fluorine-substituted hydroxyapatites (FHAs) were successfully synthesized by microwave processing. The FT-IR and Raman spectroscopic results suggest that the fluoride substitutes for the hydroxyl groups. The TEM micrographs show that the particles are of 60-80 nm size and the morphology has been slightly changed with increase in fluoride ion substitution in the microwave synthesized FHAs. In vitro dissolution studies clearly demonstrate that it is possible to fine-tune the solubility and correspondingly the biological lifetime of the FHAs by varying the amount of fluoride substitutions.

\section{References}

Boivin G 1990 in The metabolic and molecular basis of acquired disease (ed.) R D Cohen (London: Bailliere Tindall)

Chen Y and Miao X 2005 Biomaterials 261205

Groot K 1980 Biomaterials 147

Harrison J, Melville A J, Forsythe J S, Muddle B C, Trounson A O, Gross K A and Mollard R 2004 Biomaterials 254977

Itokazu M, Yang W, Aoki T and Kato N 1998 Biomaterials 19 817

Kenny S M and Buggy M 2003 J. Mater. Sci. Mater. Med. 14 923

Landi E, Tampieri A, Celotti G and Sprio S 2000 J. Eur. Ceram. Soc. 202377

Legeros R Z 1998 Adv. Dent. Res. 2164

Luis M, Rodriguez L, Judy N H and Gross K A 2003 J. Phys. Chem. B107 8316

Niwa M, Sato W, Li W, Aoki H and Daisaku T 2001 J. Mater. Sci. Mater. Med. 12227

Pullen L J and Gross K A 2005 J. Mater. Sci. Mater. Med. 16 399

Rameshbabu N, Kumar T S S and Rao K P 2005 J. Mater. Sci. 406319

Tadic D, Peters F and Epple M 2002 Biomaterials 232553

Webster T J, Ergun C, Doremus R H, Siegel R W and Bizios R 2000 Biomaterials 211803

Weiner S and Wagner H D 1998 Annu. Rev. Mater. Sci. 28271

Wopenka B and Pasteris J D 2005 Mater. Sci. Eng. C25 131

Yoon B H, Kim H W, Lee S H, Bae C J, Koh Y H, Kong Y M and Kim H E 2005 Biomaterials 262957 